This is the accepted manuscript of the article, which has been published in Acta Sociologica. 2019, 62(4), 357-371. https://doi.org/10.1177/0001699318813422

\title{
Article
}

\section{What counts as 'good sociology'? Conflicting discourses on legitimate sociology in Finland and Sweden}

\section{Johanna Hokka}

University of Tampere, Finland

\begin{abstract}
This qualitative study explores how sociology is legitimated among established Finnish and Swedish sociology professors, who are conceived as a scientific elite. Drawing upon a Bourdieusian framework, the analysis traces the discourses that define legitimate sociology in these two national contexts, and the relations between those discourses. While the scientific elite of Finnish and Swedish sociology share four discourses - the Excellence, Humboldtian, Emancipatory and Policy discourses - the relative value of each differs between the different national contexts. The Excellence discourse dominates in the Finnish data, while the Humboldtian discourse is dominant in the Swedish data. The emphases on the other two discourses also vary: in Finnish interviews, the Policy discourse holds a strong position, while the Emancipatory discourse is articulated only with nostalgia; in Swedish interviews, the Emancipatory discourse is strong and the Policy discourse weak. The results show that different national contexts produce variations in sociology's internal dynamics.
\end{abstract}

\section{Keywords}

Bourdieu, field, legitimate sociology, professors, scientific elite

\section{Corresponding Author:}

Johanna Hokka, TaSTI, Research Centre for Knowledge, Science, Technology and Innovation Studies, University of Tampere, Kalevantie 433100 Tampere, Finland.

Email: johanna.hokka@uta.fi 


\section{Introduction}

There is growing concern about how sociology will survive the university system's increasing marketisation. These concerns have aired in sociology's 'crisis' debates, ranging from anxieties about its disciplinary coherence, to concerns about the integrity of its object, to discussions of the value and purpose of sociological knowledge. The most recent high-profile debate surrounding the discipline's future was ignited by Burawoy's (2004) manifesto for public sociology in which he claimed that sociology had lost its identity because it had neglected its moral commitments and impetus. According to Burawoy, if sociology is to thrive, it must embrace public engagement and actively participate in social and political debates, in interaction with civil society. His critics argue that sociology should be conceived first and foremost as a scientific enterprise. Therefore, it should produce value-neutral knowledge, without interfering in value-laden activity (Abbott, 2007; Tittle, 2004; Turner, 2005). Ultimately, the issue at stake is the conception of legitimate sociology. By examining how legitimate sociology is defined by eminent Finnish and Swedish professors of sociology, this study provides new insights for this debate.

Alarm about the state of sociology is almost as old as the discipline itself. According to Lepenies (1988), sociology occupies a precarious academic position as a 'third culture' oscillating between the natural sciences and humanities - sometimes mimicking the scientific orientation of the former, sometimes leaning on the hermeneutic orientation of the latter. Additionally, since the sociological project has always been bound up with society, whose 
phenomena it explores, sociology's development has always been informed by sociopolitical changes (Kaukonen, 1984).

There is a considerable literature on the connection between sociology and the state, analysing sociology's manifestation and development within institutional and cognitive structures. Scholars performing macro-analysis have claimed that sociology's institutionalisation was intimately linked to the emergence of the modern secularised nation-state (Nowotny, 1991; Wagner and Wittrock, 1991). Wagner et al. (1991: 75-79) use the concept of 'discourse coalition' to elucidate the bidirectional interplay between sociology and the state that (re)shapes intellectual discourse and policy discourse alike. Empirical studies have supported the idea of the discourse coalition: for instance, comparative analyses of Mexican and US sociology (Abend, 2006) and of French and US sociology (Lamont, 2000) show that different national contexts produce national sociologies that rely on different value bases. US sociology attaches great value to objectivity and neutrality, whereas Mexican and French sociologies value social and political engagement. Such studies imply that sociology in different national contexts deploys different criteria when evaluating legitimate sociology and thinking about the social.

This interplay between sociology and the state is not mechanical, but a process of mutual inclusion and exclusion. Research on the institutionalisation of Swedish sociology has shown that the American-style empirical and quantitative orientation was embraced while the theoretical, speculative Continental approach was excluded from canonical sociology 
(Larsson, 2008; Larsson and Wisselgren, 2006). In a similar vein, analyses of the emergence of US sociology demonstrate that legitimate sociological knowledge came to be directed towards academic peers, and the extra-scientific audience was excluded from sociological publics (Evans, 2009). As Heilbron (2004) notes, when disciplines control their external and internal boundaries, they are political institutions and thereby sites of scientific struggles. Sociology's political aspect has been further revealed in studies demonstrating the marginalisation of female sociologists (Lempiäinen, 2003; Magdalenić, 2004). Likewise, analysis of the discipline's methods has shown that certain methodological 'trends' have determined scientific practices (Alastalo, 2005). Although these studies recognise the controversy surrounding the notion of legitimate sociology, they have not taken into account the complexity of sociology or the tensions among the different means of legitimation. With this in mind, I use Bourdieusian conceptual tools to make a fine-grained interpretation of the nuances in struggles over legitimate sociology.

Previously, a Bourdieusian framework has been used to analyse changes in sociology's scientific practices under science policy reforms. Albert (2003) shows that despite increasing science policy demands, field-specific internal dynamics still determine what is conceived as legitimate in Canadian sociology. Conversely, Kropp and Blok (2011) demonstrate that scientific practices in Danish sociology have been heavily imposed by the science policy. Kropp and Blok argue that national contexts should be considered in analyses of the dynamics between the field of sociology and science policy. Accordingly, this study examines internal 
dynamics in two national contexts, Finland and Sweden. By combining a Bourdieusian framework with cross-cultural analysis, this study contributes to a deeper understanding of the internal dynamics of sociology.

Finnish and Swedish sociology have been chosen as a case in point because the discourse coalition between sociology and the state has been more pronounced in Nordic countries than elsewhere (Fridjonsdottir, 1991). Finland and Sweden are often considered somewhat homogeneous due to their similar Nordic social policy regimes. However, there are important differences in their higher-education systems, science policies and general policy objectives. These differences against a backdrop of similarity provide a fruitful starting point to analyse sociology in the two national contexts. The research questions guiding this study are: what discourses do Finnish and Swedish professors of sociology use when defining legitimate sociology? What strategies are used in each discourse? How do the discourses differ between national contexts? The study is based on interviews with established sociology professors, whom I consider represent the scientific elite.

In the following, the two national contexts are described. After this, the Bourdieusian framework is outlined and the way it is used. Then, once the methods and data have been characterised, the analysis and findings along with the conclusions are presented. 


\section{National contexts of sociology}

Historical overviews of sociology in Finland and Sweden show many parallels, with both having followed general European and US theoretical and methodological trends. Like many other European sociologies, Finnish and Swedish sociologies were initially moral philosophyoriented (Fridjonsdottir, 1991). Finnish sociology was institutionalised as early as 1890 (Kaukonen, 1984). In Sweden, sociology was established in 1903, but lost its chair for decades until its re-establishment in 1947. In the interim, sociology was taught under moral philosophy, which has left its mark on Swedish sociology in a more critical profile vis-à-vis other Nordic countries (Allardt, 1993).

At the turn of the 1950s, European sociology became dominated by US sociology, which held the positivist belief that sociology should model itself on the natural sciences (Bannister, 1987; Münch, 1993). In both Finland and Sweden, the previous paradigm was challenged by American empiricism, and sociology was strongly legitimised by satisfying the state's need for knowledge (Eskola, 1992; Larsson and Magdalenić, 2015). Identifying themselves as social engineers in the service of society, sociologists participated in the making of the welfare state in the 1960s (Fridjonsdottir, 1991; Stolte-Heiskanen, 1992). These welfare state projects had different roots. In Sweden, the welfare state project was social-democratically organised and idealistic, emphasising equality and solidarity; the Finnish welfare state project, on the other hand, developed through compromises between different political alliances, and was introduced as rational planning (Kettunen, 2001). 
In the late 1970s, student revolts, the rising influence of Marxist orientation, critiques of positivism and an inclination towards the Left challenged the dominance of American empiricism in both countries (Fridjonsdottir, 1991; Stolte-Heiskanen, 1992). The 1980s witnessed the introduction of micro-level analysis, linguistic sense-making and qualitative methods, although statistical and welfare state-oriented research remained strong in Sweden (Larsson and Magdalenić, 2015; Stolte-Heiskanen, 1992). In the 1990s, the field's fragmentation was on the agenda in both countries (Alapuro, 1995; Dahlström, 1994). Today’s trends favour quantitative methods and the focus has geared towards investigating key social problems (Larsson and Magdalenić, 2015; Puuronen, 2005).

Similarities and differences are evident in institutional settings too. In Finland, sociology is a postgraduate-level subject in seven universities; in Sweden it is represented in 11 universities and eight university colleges. Finland has 44 professors of sociology, of whom under a third are women (Vipunen, 2016); the corresponding number in Sweden is nearly double that at 80, with about one quarter being women (UKÄ, 2011). The institutional settings differ in that social policy in Sweden is subsumed under sociology, whereas in Finland social policy is a free-standing discipline.

The higher-education system (HES) entails also differences. Finland has a dual system consisting of universities and universities of applied sciences. The Swedish HES is composed of older and newer universities and university colleges: the older universities receive most of the research funding while the rest focus on teaching, stratifying the Swedish system 
(Ljungberg et al., 2010). According to Larsson and Magdalenić (2015), the conditions for practising sociology vary across institutions: especially in the university colleges, sociology is bundled together with related disciplines in larger departments. Recently, sociology's science policy landscape has been strongly influenced by neoliberal doctrines in both countries. Governments have introduced performance-based funding models that measure 'excellence' and 'productivity'. It is argued that Finland, with its output-oriented core funding system, is more competitive than Sweden in this regard (Auranen and Nieminen, 2010; Geuna and Martin, 2003). I will return to how these national characteristics manifest themselves in the interview data.

\section{Theoretical framework}

Drawing upon a Bourdieusian framework, I consider sociology a field - a semi-autonomous, hierarchically structured unit of social action. For Bourdieu $(1977,1996)$, disciplines are socio-cognitive institutions constituted through scientific and political struggles. Scientific struggles are about the power to determine what is considered legitimate science. The definition of the dominant form of legitimate science, the legitimate ranking of output, and the criteria by which scholars are assessed are reproduced or transformed through these struggles. Bourdieu highlights the symbolic and cultural dimensions of these power struggles. For him, power struggles inherently include struggles over the attribution of meaning and symbolic 
value to various social practices and properties. In striving to increase their scientific authority and power, actors strive to impose definitions of legitimate science that mesh with their specific interests. Strategies serve as praxis: concrete ways of implementing a certain view of legitimacy (e.g., choices of research interest, methods or publication outlets). Similarly, distinctions, which function to distinguish 'invalid' scientific practices from 'good' ones, aim to valorise a particular view of legitimacy against competing views (Bourdieu, 1999). However, disciplinary fields are only relatively autonomous, and are influenced by external fields - above all, the field of power, that is, the modern state and its associated politics and bureaucratic categories.

In this study, I use a Bourdieusian framework to elucidate the tensional, conflicting, and hierarchical relations among discourses that address legitimate sociology. Putting the views of the scientific elite under the microscope provides an intriguing starting point to capture the sense-making of dominant actors - those who have power to define legitimate sociology. I pay attention to the strategies that epitomise certain discourses of legitimacy and the distinctions that indicate which elements are excluded from a particular view of legitimate sociology.

\section{Data and methods}

Two data sets constitute the study's empirical basis: 10 interviews with Finnish and 10 with Swedish professors of sociology. Only three of the interviewees were women (two Swedish, 
one Finnish), reflecting the male dominance of Finnish and Swedish sociology in general. The interviewees were all in their 50s-60s, and they represented a wide array of research orientations and epistemological styles. The interviews were conducted in 2012-2014 in four universities in Finland and three in Sweden. The institutions were chosen for their strength in sociology, both nationally and internationally (e.g., in the QS World University Rankings).

The study is designed to shed light on sociology as an academic field from the point of view of informants with a very special speaker position in the field (Alasuutari, 1995), not to capture the sense-making of Finnish and Swedish sociology in general. Therefore, the informants were selected on the basis of their standing in the field. They are full-time professors with permanent positions - eminent scholars with national and international research reputations. They also hold major positions in decision-making bodies through which they control the internal reproduction of the field (Bourdieu, 1984). Hence, they can be conceptualised as scientific 'elite'. From this elite position, they have the power to 'delineate and embody the values of [their] discipline[s]' (Becher, 1989: 3) and to make decisions about what constitutes legitimate science in the field (Bourdieu, 1984). This renders the sensemaking of these informants especially relevant.

My analytical perspective applies a cross-cultural approach that scrutinises the research object in two cultural contexts (Gordon and Lahelma, 2004). Adopting a discursive reading, I have traced wider, relatively coherent cultural sense-making structures that indicate views of legitimate sociology (Chouliaraki and Fairclough, 1999). Interviewees were asked to describe 
the most crucial changes within sociology, the current state of the field, what is valued in sociology in general, and how they themselves understand good sociology. In the analysis, 'legitimate' and 'good' sociology are regarded as referring to the same thing.

For the analysis, I first selected all extracts representing views on good sociology. Second, from these extracts I inductively generated internally coherent data-driven classifications, which I dubbed the Excellence, Humboldtian, Emancipatory and Policy discourse, to illustrate the discourse's content. Each discourse was utilised by more than one professor, and some professors employed multiple discourses. Third, I considered each extract in relation to the volume of the discursive space (Alasuutari, 1996) constituted by the full data set, and I examined relationships among the discourses in each nation's data. Through this contextsensitive close reading, I formed the categories 'dominant', 'strong' and 'weak' to characterise the position of each discourse in each national data set. A 'dominant' discourse is strongly supported and has power over the other discourses in that they must acknowledge it. A 'strong' discourse has supporters, space and sovereignty, but lacks power over the other discourses. Finally, a 'weak' discourse holds a fragile position and must defend its existence against the others. This categorisation conveys the internal dynamics of sociology.

I will next present the four discourses, along with their strategies. For each discourse, the basic principle is the same in the two countries, but each has national specificities, which I call the Finnish or Swedish version of the discourse. In order to assure full anonymity, all personal and institutional identifiers have been removed from the extracts. The accompanying 
interviewee-specific code is composed of a country indicator ('FIN' for Finland, 'SWE' for Sweden) and interviewee number. In the results section, I indent longer quotations, while shorter extracts are enclosed in quotation marks. I will begin by presenting the two dominant discourses - the Excellence and Humboldtian discourses - and then present the Emancipatory and Policy discourses.

\section{Excellence discourse}

In the Excellence discourse, legitimate sociology is a scientific enterprise, with legitimisation accomplished via top-level academic outcomes. Legitimacy is assessed through the internal values of science. The aim is to be at the forefront of the field. The international scientific community and fellow researchers represent the audience to whom scientifically ambitious sociology must speak. Moreover, there is an objective to contribute to the international scientific arena. This discourse also strives to maintain sociology's scientificity by advocating the production of unbiased knowledge, and by opting out of extra-scientific debates. This is the dominant discourse in Finnish interviews, but it has a weak position in the Swedish data. I will begin with the discourse's Finnish version.

The first strategy in aiming for the top is to embrace the competitive spirit. Competition is deemed a rational endeavour that sorts the wheat from the chaff, eliminating substandard research from the field: 
I think the competitive funding system is an excellent way to ensure quality assurance in reaching for the top. Science will not progress without competition. (FIN4)

Here, competition is characterised as necessary for scientific progress. Although competition has always been part of the academic ethos, this discourse presents success in international competition as correlating directly with research quality. In order to achieve success and 'contribute something new to the international arena', one must specialise. Furthermore, if one is to be involved in this competition, international publishing is a must. This leads in turn to the second strategy: publishing international peer-reviewed articles in top-tier journals:

This competition, that you have to publish internationally, I have internalised it completely, and I don't want anyone I supervise to write anything in Finnish. If you want to work in academia, you have to write internationally refereed articles. (FIN10)

Here, a distinction is made from writing in Finnish, which is portrayed as lacking real academic value. Only articles in international peer-reviewed journals can impart scientific legitimacy. These journals' ascendancy is evident in depictions of publications aimed at the wider public as 'light' or 'sociologically poor' and thus not meeting academic standards:

Certainly, society respects the kind of research that is trendy and takes an ostentatious stand on current issues, in a flashy way. But it is internationality and international publishing that count in academia. This is what brings appreciation. (FIN4)

This dismissal of popular writing reveals the hegemony of international peer-reviewed 
articles. Simultaneously, the disdain for publication formats other than peer-reviewed articles implies that sociology should not be involved in extra-scientific struggles and should solely provide neutral knowledge to ensure its scientific legitimacy. This is also evident in the discourse's distancing from politically involved sociology:

Our demographers, who are studying death rates, health inequalities, and such, have very strong, <laughs $>$ simple and crystallised political messages to which everyone should listen. But I don't [have one]. (FIN5)

Politically engaged sociology is something that others do but scientifically respectable sociology does not: 'there are those who want to actively comment on all sorts of political incidents'. Similarly, a distinction is made between current sociology and earlier generations when the field 'was whispering in President Kekkonen's ear'. The 'national mission' of sociology in the 1960s-1970s and its cooperation with the government authorities are considered to have been detrimental to sociology's scientific standing. This distinction from politically engaged sociology is a third strategy for concretising how sociology should stick to its mission as a scientific enterprise, without interfering in politics.

In the Swedish version too, the first strategy is to write peer-reviewed articles:

As they press us to produce more articles, people try to produce articles instead of monographs and also produce more. I think that's good. (SWE8)

As in the Finnish version, a distinction is made between sociology today and in the past, when 
'you could be a good sociologist in Sweden having published practically nothing in English.' Unlike with earlier generations' 'inward-looking sociology', international publishing is considered a real advantage for sociology's scientific development, since 'scholars are forced to contextualise their research and convert it into a form that is accessible to people from other parts of the world.'

However, unlike the Finnish version, which welcomes peer-reviewed articles as a determination of scientific legitimacy, the Swedish version depicts such publications as more of a necessity, 'something we have to do to survive' or 'a reality we need to face'. Overall, the juxtaposition of the two data sets shows that the Finnish version of the discourse, with its explicit strategies, is keener to embrace the competitive spirit and concomitant striving for excellence than the Swedish version.

\section{Humboldtian discourse}

Like the Excellence discourse, the Humboldtian discourse assesses the legitimacy of sociology in terms of the internal values of science. In the Humboldtian discourse, however, legitimacy is rooted in the idea of sociology as a general social science that differs from other disciplines in its ability to capture and explain human reality through grand theories. Legitimate sociological work should contribute creative conceptualisations and theoretical models to social scientific debate. This is the dominant discourse in the Swedish interviews. It 
appears in the Finnish interviews too, but there its standing is problematic. I will describe this after presenting the Swedish version.

The first strategy for expressing 'stylish concepts' and 'new theoretical insights' is to write monographs:

I like individuals who have written something that really means something, those books, perhaps with a more essayistic style, have a personal voice and exert influence for a long time. (SWE4)

The book format enables profound immersion in the research topic, examining phenomena from many angles. The reference to a scholar's unique intellectual style implicitly ascribes value to sociology that describes social phenomena in a vivid and expressive manner.

While books are defined as a legitimate publication format, articles are considered 'boring' and 'simplifying':

Today you are supposed to produce a trickle of articles that follow the same recipe. They are so boring that your reader falls asleep. But you will have a long list of publications. I think that the mature individual should practise selfreflection. A good society should set aside time and resources for reflection. But then we are back to the Humboldt thing where students meet real researchers and researchers write books, not papers. (SWE7) 
The rigid, formal structure of articles does not allow the multidimensional discussion of topics that legitimate sociology demands. Meanwhile, the 'ranking business' is criticised as an artificial, superficial way to evaluate research quality. It fails to assess aspects of true quality such as originality, theoretical creativity and careful argumentation. This criticism of forced article production and journal rankings is coupled with a discrediting of research that is aligned with the Excellence discourse. Such research is represented as opportunistic, in stark contrast to the conscientious research consistent with the Humboldtian discourse. This distinction, which serves as a second strategy, valorises the Humboldtian discourse by presenting it as highly moral.

The third strategy celebrates the Humboldtian idea of the unity of research and teaching:

Postgraduate students, that's the motivation in itself, because you can be proud of them: 'Oh my God, I've been a part of this.' And it's just nice to meet and sit and talk. And you are happy for their sake because you know that they have invested a lot of time. (SWE8)

Teaching and supervising postgraduates is described as inspiring, enabling the cultivation of fresh perspectives and the development of theoretical and methodological thinking. These expressions reflect a desire to support the offspring on their academic path. Furthermore, this strategy implies the objective of passing sociological heritage on to the next generation through the important act of writing textbooks. 
Interestingly, according to this discourse, Humboldtian values are not threatened by tendencies in science policy or in the field of sociology itself. Indeed, this discourse holds that the strong standing of Humboldtian values in sociology prevents external factors from discrediting them. This is evident in the strong support for theoretical research against quantitative research:

Clearly the kind of high-flying, very quantitative researchers who come up with fancy results are respected. But in sociology I think that the good theory people are still viewed with great respect. (SWE6)

In the Finnish version too, book-writing is the first strategy for meeting the criteria of legitimate sociology.

The one scholar whom I appreciate writes books that are classics in the sense that they have a lasting influence on social scientific discussions and they inspire the generations to come. This scholar is not international at all, and he seldom publishes, but all the books he has written are important books. (FIN4)

It is conspicuous in this extract that while 'classics' are appreciated, internationalisation and publication rates are still acknowledged as crucial definers of a scholar's research profile. The reference to internationalisation and publication rates reflects their ascendancy amid criteria for scientific legitimacy. 
The Finnish version too expresses disdain for article production, portraying it as 'articlemilling' that 'reduces space for intellectual thinking' or yields 'short-sighted', 'half-arsed' and 'superficial' outcomes. In line with this, the 'real research work' of the Humboldtian discourse is distinguished from the unscrupulous mindset of the Excellence discourse. This distinction thus operates as a second strategy by highlighting the high morals of Humboldtian values and challenging the dominance of the Excellence discourse.

The third strategy in the Finnish version involves marrying teaching with research. Postgraduate supervision is presented as generating 'paternal' feelings or 'enjoyable, insightful moments with postgrads' from which fresh scientific ideas may sprout. However, such references are connected to anxiety about supervisees' futures with regard to funding and employment.

The most striking feature of the Finnish version is that the discourse is consistently framed with 'used to be, not any more' phrasing:

When I became a researcher, cultural studies was being introduced in Finnish sociology. Then, there was a prevalent playfulness and positive openness to what sociology could be. That was then. Nowadays, 'caterpillar' sociology overrides this; it's very serious, very masculine, the kind that emphasises internationality and quantity. The idea that everything can be sociologically interesting was nurtured within cultural studies. It was possible to really ponder things, not just to produce strong data on societally important questions. (FIN10) 
The Humboldtian discourse is thus described through nostalgic yearning. This discourse's cherished principles are portrayed as things of the past. Science policy plays a role, but the field itself has also eagerly followed the trend of transforming intellectually sparkling, pluralistic sociology into sociology that emphasises quantitative, internationally oriented research and espouses a rigid definition of legitimate sociology. Accordingly, the Finnish data paint a picture of the triumphal march of the Excellence discourse. According to expressions in the Swedish data, contrastingly, one need not fear for Humboldtian values: they command great respect in the field, irrespective of the external push for article production.

\section{Emancipatory discourse}

In the third discourse, legitimate sociology refers to sociology as a highly critical field. This sociology strives to 'bring change' to society by highlighting hidden social inequalities. Legitimate research questions centre on 'discriminatory practices' or 'marginalised' groups. The aim is to empower people by increasing their awareness via sociological knowledge. Therefore, to be legitimate, sociology should speak to the masses. This discourse has a strong position in the Swedish interviews; it is evident in the Finnish data only in weak form, as nostalgic recollection. I present the Swedish version first.

The first strategy is to rely on sociology's theoretical basis to deepen understanding of repressive social structures. 
It's the discipline where you find a kind of critical approach, which I think is important. I believe that there should always be social science that does the same kind of work journalists are supposed to - to scrutinise our power institutions - but in a more in-depth way by using theory. (SWE2)

Theories provide a novel way to understand and broaden the scope of human reality. In holding the theoretical sophistication of sociology in high regard, the Emancipatory discourse ties in with the Humboldtian; however, whereas the latter values theoretical cultivation for its own sake, in the Emancipatory discourse theories serve as strategy. They give a backbone to critical arguments against existing social structures. Moreover, while the Humboldtian discourse anchors its morality in diligent intellectual endeavour, the Emancipatory discourse derives its morality from the social outcomes of research.

Sociology's combination of theoretical profundity and moral intention constitutes its crucial difference from other fields:

You have changed your sex or you are an ordinary homosexual and tell us of your experience. We [sociologists] can contribute to understanding the body and the mind and the apprehension of others. The other disciplines - psychology - they are so old-fashioned. They can almost say: 'You need therapy.' It's like the Catholic Church. In that way, we are also attractive to newcomers who have not been to university before: working-class youth and children of immigrants. And 
they are welcome in sociology. It may be their first encounter with academia, and it's a better encounter than with the other disciplines. (SWE4)

Here, sociology is described as a discipline that 'takes everyone in', whereas other disciplines adopt an arrogant and disapproving stance towards non-normative sexualities or people from lower strata. Furthermore, other social sciences are depicted as conservative, interested merely in 'giving the correct answers'. Sociology, in contrast, examines social reality openmindedly and is willing to question prevailing social structures. Through this distinction, sociology is represented as a source for social dynamics. This distinction serves as a second strategy, thereby linking the legitimacy of sociology to its interest in defending humanity.

For interaction with people whose social conditions sociology undertakes to improve, the third strategy is to write in their native language:

I think it would be a really bad thing if all sociology produced in this department were written in English. We must also communicate with the wider public. (SWE1)

This strategy depicts a sociology 'for all', not just for scientific peers: legitimate sociology should speak to civil society. This discourse conflicts with the Excellence discourse, where it is publishing for the international scientific community that confers scientific legitimacy.

Although the Emancipatory discourse emphasises sociology's social engagement, it distances itself from sociological research that serves government machinery. This distinction from 'social-engineering sociology' acts as a fourth strategy: 
The idea was that we could create a referral society if we had knowledge about people's living conditions and the reform activities were based on social knowledge. But that's not the case now. We have left these rationalistic ideals for society, and we have more a nuanced view than top-down, bottom-up steering. (SWE3)

The aim is to stress that real, revolutionary sociology cannot be harnessed for government ends. Instead, sociology must set its own research agenda, to achieve knowledge that is not polluted by the vested interests of the power elite.

While recognised in the Finnish interviews, this discourse is connected with the past: it reflects something Finnish sociology used to engage in but no longer does. The field is accused of being too tame, not exerting enough effort to 'reveal the harsh structural violence' in society:

Many sociologists' studies are too mild. We should make more of an effort. I think it is revealing that the kind of sensation aroused by research such as Tandem and Meteli does not arise anymore. The social relevance of sociology isn't worth much at the moment. (FIN7)

The Tandem and Meteli studies were Marxist-influenced and focused on improving conditions for blue-collar workers in the 1970s. The message is that a sociology willing - and above all, able - to raise public awareness of unequal societal structures is a thing of the past. The Emancipatory discourse, like the Humboldtian discourse, is expressed through nostalgic recollection: 
In the 1970s, there could be discussions week after week in Helsingin Sanomat [Finland's largest-circulation national daily newspaper] about one article in Sosiologia [peer-reviewed Finnish sociology journal] where the main finding was that the legal system does not work impartially $<$ sighs $>$ with respect to young offenders; youth from the lower strata are given harsher sentences. That was then. Now if someone published this sort of article, there would be a profound silence. (FIN6)

External fields - such as gatekeeping news media, or science policy with its strong push for international peer review - as well as sociology itself are accused of erecting barriers to the fulfilment of emancipatory values. Although Swedish interviewees acknowledge challenges to emancipatory sociology, such as policy demands for research that has social and economic utility, they indicate that these external challenges have not discredited the values cherished in the Emancipatory discourse. The difference between the Finnish and Swedish versions is that the Emancipatory discourse fares well in the Swedish version, while in the Finnish version the principles it embodies have been thoroughly discredited, by external tendencies and internal dynamics alike.

\section{Policy discourse}

In the Policy discourse, legitimate sociology provides knowledge for political decisionmaking. To be legitimate, research must be socially useful and relevant, targeted at 
government authorities and administrative bodies. This discourse relies on sociology's past, drawing on a legitimacy inherited from the era when it actively participated in the making of the welfare state. In this discourse, this involvement with socio-political planning represents sociology's traditional identity. The Policy discourse holds a strong position in the Finnish data, which I discuss first. In the Swedish data there are hints of it, but its position is weak.

The first strategy is to offer empirical knowledge in a convenient package:

This research approach, wherein you can combine multiple types of methodological know-how in one package, serves as a very concrete way to practise the traditional kind of sociological research. It doesn't require major theoretical discussions. If you are doing this kind of research, the call for the research is so strong that you have to run out there to speak to the ministry, to the municipalities, etc. (FIN6)

In contrast to the Humboldtian valorisation of sophisticated theorising, here conceptual and theoretical ambition are unnecessary. The aim is to find real evidence; hence methods and their proficient use are what matters. This discourse speaks for a more instrumental, applied sociology, whose role is to solve specified problems. Unlike the Emancipatory discourse, which refuses to adopt the problem definitions of the political elite, the Policy discourse is willing to answer the 'call' of administrative bodies.

The second strategy defines legitimate sociology's research object by distinguishing it from 'nice-to-know' research: 
I respect the kind of research that is useful to society. Many scholars are doing their research with only an 'I am just interested in this' attitude. I don't think society is obliged to fund research that is done for the sake of your own interests. The research must be useful to society. (FIN3)

The science-society contract is highlighted. In this discourse, it is morally dubious to research 'all the bizarre, marginal issues' that originate solely from one's personal interests. Instead, research should be 'crucial for the development of Finnish society'. Through this strategy, the Policy discourse distinguishes socially relevant knowledge from the purely academically oriented research of the Humboldtian discourse, which respects curiosity-driven work. To be legitimate, sociological research should provide 'real facts' for policymaking.

The 1960s and 1970s, when sociology played a role in developing the welfare state, are held up as a success that sociology should replicate. This 'story of the golden age' is a third strategy to construct sociology's legitimacy. The discipline's societal significance is far too often neglected today by political decision makers and society. In the Policy discourse, reclaiming its role as a sociopolitical actor would improve sociology's legitimacy in relation to other fields and society at large:

I hope for there to be enough wisdom in society that it would still finance sociology. Sociological research is essential for merely securing the functionality of society, although many are not ready to acknowledge this. Instead, we are deemed scholars of platitudes or trivial research. Still, sociological research has 
had great significance, for example, in developing the Finnish higher-education and school system, and through that the well-being of the whole society. (FIN4)

Although sociology seems to have lost its legitimacy in Finnish society since the golden age, this discourse predicts that its political role will strengthen. Expressions within this discourse convey that sociology has 'shaped up' in terms of producing policy-relevant knowledge, and that policy-relevant sociology is making a comeback after years in the wilderness.

The Swedish data, in contrast, give a diminishing role to the Policy discourse:

If you really want to make an impact in the world, I would not recommend becoming an academic at all, rather politicians, teachers or whatever. Maybe today becoming a sociologist is not the perfect choice. It's a very good choice if you want to understand society, but in terms of politics it has gone downhill so much. (SWE10)

The Swedish interviews reflect a withdrawal from policy-oriented sociology. Simultaneously, they blame science policy for the lack of interaction between sociology and politics, since science policy's emphasis on international peer-reviewed articles imposes a barrier to sociology that practises policy-oriented research. The crucial difference between the Finnish and Swedish data lies in the muted nature of the Policy discourse in the Swedish interviews, and indications of that discourse's immanence in the Finnish data. 


\section{Conclusion}

This study set out to explore how legitimate sociology is defined by the scientific elite of sociology in Finland and Sweden. Four discourses have been discerned: the Excellence, Humboldtian, Emancipatory and Policy discourses. These parallel Burawoy's (2004) fourfold typology of professional, critical, public and policy sociology. Similar to the Excellence discourse, professional sociology generates instrumental knowledge for an academic audience, improving the discipline's scientific grounding. Critical sociology resembles the Humboldtian discourse, which provides reflexive knowledge for an academic audience by examining the moral foundations of sociological knowledge-making. Policy sociology produces instrumental knowledge and finds solutions to problems defined by political decision makers, corresponding to the Policy discourse. Finally, public sociology, which produces reflexive knowledge and empowerment for extra-academic audiences, parallels the Emancipatory discourse.

This consistency with Burawoy's typology implies that there is something fundamental and inherent in sociology: a shared core that produces the same kind of differentiation in the US and in these two Nordic sociologies, even though they are rooted in different sociopolitical contexts. In Bourdieu's (1977) terms, this division could be interpreted as an expression of doxa: a penetrable, unconscious sense-making structure of the field. Additionally, this similarity may indicate the symbolic domination of the vocabularies of US sociology - what Bourdieu and Wacquant (1999) call the 'cunning of imperialist reason'. The imposition of US 
sociology as the universal legitimate discourse is manifested in the homogenisation of the social sciences. Prior literature supports this interpretation since Finnish and Swedish sociology has been strongly influenced by US sociology, adopting its methodological and epistemological trends. However, according to Burawoy, at least as regards US sociology, these four types are imbalanced. The instrumental orientation represented by professional and policy sociology dominates, while room for the reflexive orientation of critical and public sociology is limited. For Burawoy, this imbalance reflects a wider constellation of interests and power struggles. Under 'raw capitalism' in which 'money and power speaks louder than values and influence,' the instrumental orientation, which supplies money and prestige, overwhelms the reflexive orientation (Burawoy, 2004: 18).

The findings of this study, however, extend beyond Burawoy's formulation by pointing to striking national differences in the relative value given to these four types. In the Finnish case, the dominance of the Excellence discourse entails a strict definition of legitimate sociology: writing international top-tier articles is the only viable strategy for scientific legitimacy. Additionally, the Policy discourse is strong in Finland. The dominance of the Excellence discourse and strong presence of the Policy discourse imply that in Finnish context the view of what constitutes legitimate sociology is monopolised by these two camps, which both have sovereign space in the field. According to these data, Swedish sociology is an intellectual enterprise that connects grand theories to human emancipation and is rooted in criticality and social justice. In Burawoy's terms, the instrumental orientation is dominant in Finland, while 
the reflexive orientation dominates in Sweden. In this respect, Finnish sociology seems to be more under the influence of US sociology than its Swedish counterpart. Thus, irrespective of the shared core, the internal dynamics of sociology take different forms and orientations in different national contexts.

These differences in the internal dynamics of sociology arguably reflect the two countries' divergent welfare state projects and general policy objectives (Heiskala and Kantola, 2010; Kettunen, 2001). The strength of the Emancipatory discourse in the Swedish data may embody the idealistic nature of the welfare state project in Sweden. In Finland, by contrast, the welfare state project was less idealistic, and was rooted in rational consensus-building among political coalitions. The strong position of the Policy discourse in the Finnish data may relate to this corporatism of the national welfare state project. To draw on the terminology of Wagner et al. (1991), these differences can be conceptualised as national differences in discourse coalitions. In each national context, the discourse coalition between sociology and the state takes different forms, shaping the way legitimate sociology is viewed.

In a departure from previous studies that demonstrated the hegemony of quantitative, welfare state-oriented research in Swedish sociology (Fridjonsdottir, 1991; Larsson and Magdalenić, 2015), the weakness of the Policy discourse in the Swedish data is surprising. This inconsistency may relate to this study's focus on 'top' sociology departments. As mentioned above, the old universities receive the largest share of funding and dominate the research sector, stratifying Sweden's HES. According to Hallonsten and Hugander (2014), despite 
ascendant managerialism, classic academic norms and ideals have remained strong in Sweden because of the power of the old universities. It seems that Swedish sociology in established institutions can 'afford' to focus on reflexive and non-instrumental research, draw on traditional academic values and ignore the science policy push. Although both countries have reformed their science policy in accordance with neoliberal doctrine, and all-encompassing competition has increased, the Finnish science system is more competitive than the Swedish (Auranen and Nieminen, 2010). The dominance of the instrumental orientation and the weakness of the reflexive orientation in the Finnish data may embody competitive research environment and strong science policy steering in Finland. In this respect, the Finnish case resembles Danish sociology, where the science policy push has made the instrumental orientation dominant at the expense of the reflexive orientation (Kropp and Blok, 2011). Conversely, Sweden is similar to Canada, where the field-specific logic of sociology has had a bigger role in shaping the views of legitimate sociology (Albert, 2003). Overall, Finnish sociology seems to be strongly challenged by the science policy field and more dependent on the 'raw' realities of capitalism than its Swedish counterpart.

This study shows that national contexts mould the ways the field-specific dynamics of sociology are constructed. In this study, the focus was on the sense-making of sociology's scientific elite. In future studies, it would be important to scrutinise how other strata especially newcomers, who contribute to the reproduction of the field - define legitimate sociology. 


\section{Acknowledgements}

I wish to thank Milla Annala, Jari Aro, Erkki Kaukonen, Reetta Muhonen, Paula Nissila“, Pia Vuolanto and especially my $\mathrm{PhD}$ supervisors Oili-Helena Ylijoki and Lea Henriksson for their valuable comments on previous versions of the paper. I also thank five anonymous reviewers and the editorial team at Acta Sociologica, all of whom provided insightful and detailed comments.

\section{Funding}

The author(s) disclosed receipt of the following financial support for the research, authorship, and/ or publication of this article: The research carried out in this study has been made possible by the financial support from the Faculty of Social Sciences of the University of Tampere and Finnish Cultural Foundation.

\section{References}

Abbott A (2007) For humanist sociology. In: Clawson D (ed.) Public Sociology: Fifteen

Eminent Sociologists Debate Politics and the Profession in the Twenty-first Century.

California: University of California Press, pp.195-209.

Abend G (2006) Styles of sociological thought: sociologies, epistemologies, and the Mexican and US quests for truth. Sociological Theory 24(1): 1-41.

Alapuro R (1995) Review essay: structure and culture: Finnish sociology, 1990-94. Acta Sociologica 38(2): 167-180.

Alastalo M (2005) Metodisuhdanteiden mahti: lomaketutkimus suomalaisessa sosiologiassa 1947-2000. Tampere: Vastapaino.

Alasuutari P (1995) Researching Culture: Qualitative Method and Cultural Studies. London: Sage. 
Alasuutari P (1996) Toinen tasavalta: Suomi 1946-1994. Tampere: Vastapaino.

Albert M (2003) Universities and the market economy: the differential impact on knowledge production in sociology and economics. Higher Education 45(2): 147-182.

Allardt E (1993) Scandinavian sociology and its European roots and elements. In: Nedelmann B and Sztompka P (eds) Sociology in Europe: In Search of Identity. Berlin: de Gruyter, pp.119-141.

Auranen $\mathrm{O}$ and Nieminen M (2010) University research funding and publication performance: an international comparison. Research Policy 39(6): 822-834.

Bannister RC (1987) Sociology and Scientism: The American Quest for Objectivity, 18801940. Chapel Hill: University of North Carolina Press.

Becher T (1989) Academic Tribes and Territories: Intellectual Enquiry and the Cultures of Disciplines. Milton Keynes: Society for Research into Higher Education/Open University. Bourdieu P (1977) Outline of a Theory of Practice. Cambridge: Cambridge University Press. Bourdieu P (1984) Homo Academicus. Paris: Minuit.

Bourdieu P (1996) The Rules of Art. Cambridge: Polity Press.

Bourdieu P (1999) The specificity of the scientific field. In: Biagioli M (ed.) The Science Studies Reader. New York: Routledge, pp.31-50. 
Bourdieu P and Wacquant L (1999) On the cunning of imperialist reason. Theory, Culture and Society 16(1): 41-58.

Burawoy M (2004) For public sociology. American Sociological Review 70(1): 4-28.

Chouliaraki L and Fairclough N (1999) Discourse in Late Modernity: Rethinking Critical Discourse Analysis. Edinburgh: Edinburgh University Press.

Dahlström E (1994) Contemporary Swedish sociology: a personal view. Acta Sociologica 37(1): 75-92.

Eskola A (1992) Sosiologian uudistuminen 1950-luvulla. In: Alapuro R, Alestalo M, HaavioMannila E, Allardt E, Haatanen P, Eskola A and Stolte-Heiskanen V (eds) Suomalaisen sosiologian historia. Helsinki: WSOY, pp.241-281.

Evans MS (2009) Defining the public, defining sociology: hybrid science - public relations and boundary-work in early American sociology. Public Understanding of Science 18(1): 522.

Fridjonsdottir K (1991) Social science and the 'Swedish model': sociology at the service of the welfare state. In: Wagner P and Wittrock B (eds) Discourses on Society: The Shaping of the Social Science Disciplines. Dordrecht: Springer, pp.247-270.

Geuna A and Martin BR (2003) University research evaluation and funding: an international comparison. Minerva 41(4): 277-304. 
Gordon T and Lahelma E (2004) Vertaileva ja poikkikulttuurinen tutkimus. In: Alapuro R and Arminen I (eds) Vertailevan tutkimuksen ulottuvuuksia. Helsinki: WSOY, pp.97-111.

Heilbron J (2004) A regime of disciplines: towards a historical sociology of disciplinary knowledge. In: Camic C and Joas H (eds) The Dialogical Turn: New Roles for Sociology in the Postdisciplinary Age. Oxford: Rowman and Littlefield, pp.23-42.

Hallonsten O and Hugander O (2014) Supporting 'future research leaders' in Sweden: Institutional isomorphism and inadvertent funding agglomeration. Research Evaluation 23(3): 249-260.

Heiskala R and Kantola A (2010) Vallan uudet ideat: hyvinvointivaltion huomasta valmentajavaltion valvontaan. In: Pietikäinen P (ed.) Valta Suomessa. Helsinki: Gaudeamus, pp.124-148.

Kaukonen E (1984) Suomalainen sosiologia tieteentutkimuksen valossa. Sosiologia 21(2): $128-138$.

Kettunen P (2001) The Nordic welfare state in Finland. Scandinavian Journal of History 26(3): 225-247.

Kropp K and Blok A (2011) Mode-2 social science knowledge production? The case of Danish sociology between institutional crisis and new welfare stabilizations. Science and Public Policy 38(3): 213-224. 
Lamont M (2000) Comparing French and American Sociology. Tocqueville Review 21(1): $109-122$.

Larsson A (2008) Textbooks, syllabuses and disciplinary formation in Sweden. Current Sociology 56(2): 235-251.

Larsson A and Magdalenić S (2015) Sociology in Sweden: A History. Basingstoke: Palgrave Macmillan.

Larsson A and Wisselgren P (2006) The historiography of Swedish sociology and the bounding of disciplinary identity. Journal of the History of the Behavioral Sciences 42(2): $159-176$.

Lempiäinen K (2003) Sosiologian sukupuoli: tutkimus Helsingin ja Tampereen yliopistojen sosiologian kurssikirjoista. Tampere: Vastapaino.

Lepenies W (1988) Between Literature and Science. Cambridge: Cambridge University Press.

Ljungberg D, Johansson M and McKelvey M (2010) Polarization of the Swedish university sector: structural characteristics and positioning. In: McKelvey M and Holmén M (eds) Learning to Compete in European Universities: From Social Institution to Knowledge Business. Cheltenham: Edward Elgar, pp.128-159.

Magdalenić S (2004) Gendering the Sociology Profession: Sweden, Britain and the US. Stockholm: Almqvist and Wiksell International. 
Münch R (1993) The contribution of German social theory to European sociology. In:

Nedelmann B and Sztompka P (eds) Sociology in Europe: In Search of Identity. Berlin: de Gruyter, pp.45-67.

Nowotny H (1991) Knowledge for certainty: poverty, welfare institutions and the institutionalization of social science. In: Wagner P, Wittrock B and Whitley R (eds) Discourses on Society: The Shaping of the Social Science Disciplines. Dordrecht: Kluwer Academic, pp.23-44.

Puuronen V (2005) Suomalaisen sosiologian paradigmoja 1960-luvulta nykypäivään. Sosiologia 42(1): 50-62.

Stolte-Heiskanen V (1992) Sosiologia vakiintuneena tieteenä. In: Alapuro R, Alestalo M, Haavio-Mannila E, Allardt E, Haatanen P, Eskola A and Stolte-Heiskanen V (eds) Suomalaisen sosiologian historia. Helsinki: WSOY, pp.287-330.

Tittle CR (2004) The arrogance of public sociology. Social Forces 82(4): 1639-1643.

Turner JH (2005) Is public sociology such a good idea? American Sociologist 36(3-4): 27-45.

UKÄ (2011) Statistical database. Swedish Higher Education Authority. Available at: http://statistik.uka.se/ (accessed 2 October 2018).

Vipunen (2016) Statistical database. Ministry of Education and Culture and National Board of Education. Available at: http://vipunen.csc.fi/ (accessed 2October 2018). 
Wagner P and Wittrock B (1991) Analyzing social science: on the possibility of a sociology of social sciences. In: Wagner P, Wittrock B and Whitley R (eds) Discourses on Society: The Shaping of the Social Science Disciplines. Dordrecht: Kluwer Academic, pp.3-24.

Wagner P, Wittrock B and Wollmann H (1991) Social science and the modern state: policy knowledge and political institutions in the United States. In: Wagner P, Weiss C, Wittrock B and Wollmann H (eds) Social Science and Modern States: National Experiences and Theoretical Crossroads. Cambridge: Cambridge University Press, pp.28-87. 